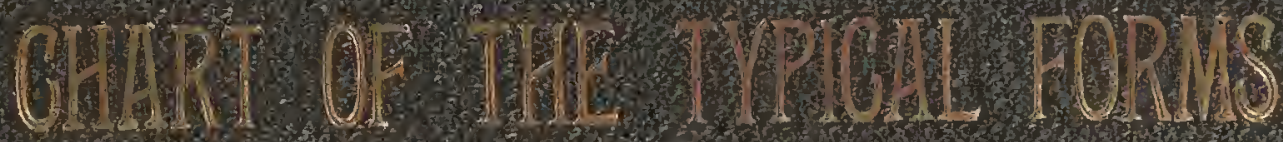

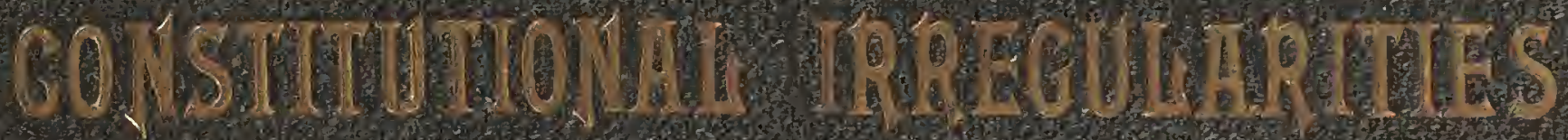

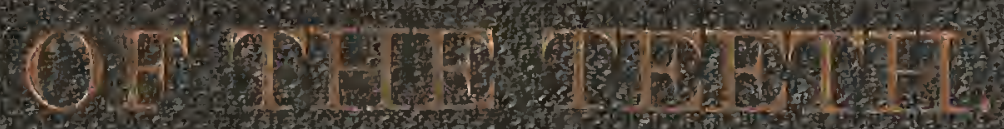




\section{Edward $\mathcal{H}$. Angle}

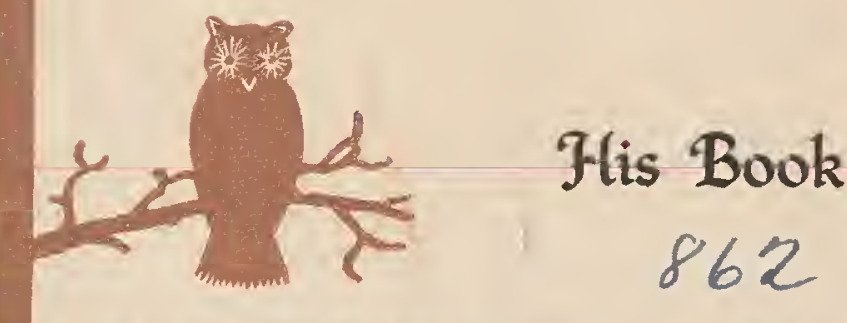


$(\ln )$ (n)

$$
\text { ( ) }
$$

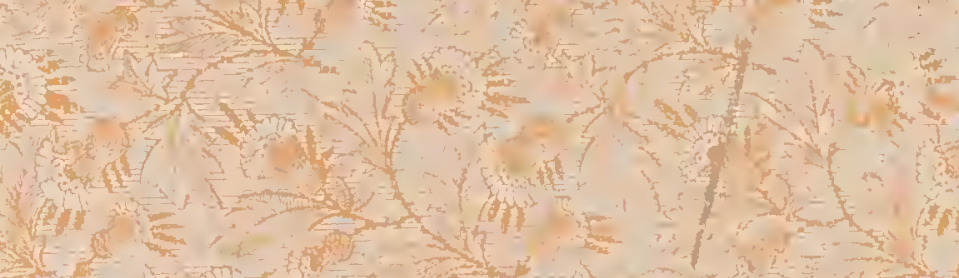$$
l^{n}=
$$

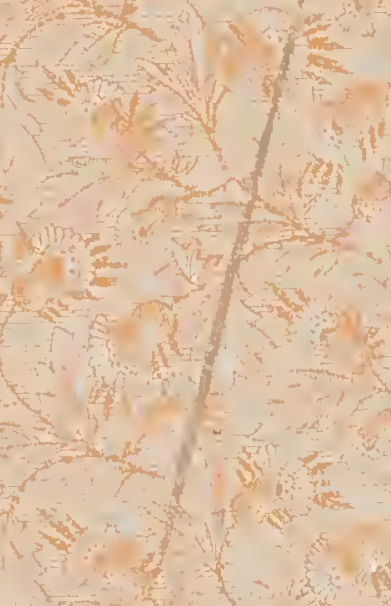

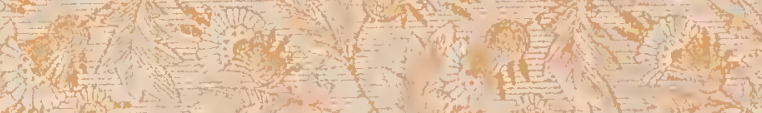
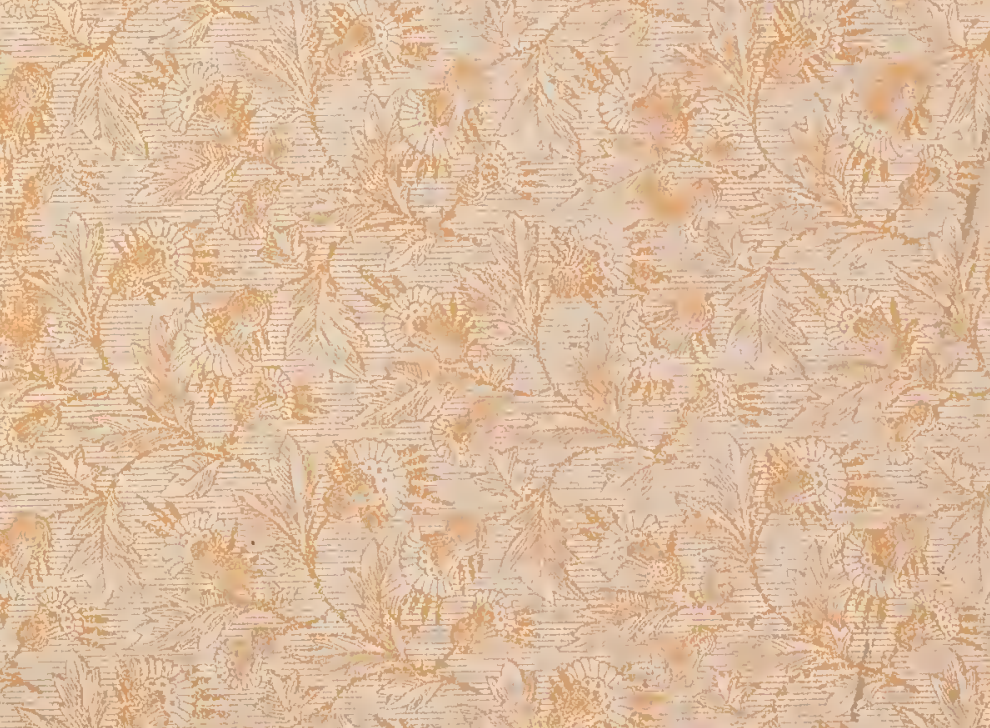


\section{CHART OF TYPICAL FORMS}

\section{GONSTITITIONAL * IRREGILARITIES}

\section{OF THE TEETH.}

By Eugerine S. TIALBoT, M. D., D. D. S.,
Professor of Dental Surgery, Woman's Medical College; Lecturer on Dental Surgery and Pathology, Rush
Medical College, Chicago; Author of "The Irregularities of the Teeth and their Treatment;" Honorary
Member of the American Medical Association; Member of the Chicago Medical Society;
ciation; Member of the Illinois State Dental Society; Member of the Chicago Dental
Club; Honorary Member of the Odontologischen Gesellsehaft, Berlin, Ger-
many; Honorary Member of "L'Odontologie," Paris, France, ete., ete.

PUBLISHED BY

The Wilmington Dental Manufacturing Company, PHILADELPHIA. 


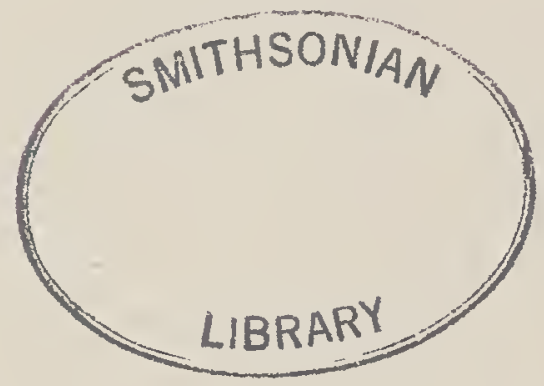




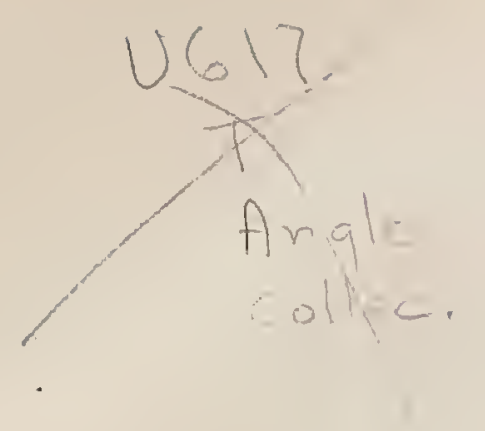

PREFACE.

The object of publishing this work is to illustrate the typical forms of Constitutional Irregularities of the jaws and teeth, so that the teacher and student may readily comprehend the various positions which the jaws and teeth may assume.

Constitutional irregularities of the jaws and teeth are those aberrations of development of those parts that are formed coincidently with the development of the general osseous system, and are not the result of accident. They are produced either by excessive or arrested development of the maxillary bones.

Deformities of the jaw, as illustrated by plates IX-XVI, may be produced also by a local cause, viz.: the forward movement of the first permanent molar, which places the jaw in the same condition as regards size as would arrest of development. The manner of the formation of each variety is described in my work upon "Irregularities of the 'Teeth."

All the plates were made from drawings and models by the author, and were reproduced in colors by the Shober \& Carqueville Lithographing Company, Chicago, Ill. These illustrations are typical, and are accurate representations of cases which have occurred in the practice of the author from time to time for the past fifteen years. While the. general outline of the jaws and teeth is the same, in no two cases are they exactly alike in detail.

These forms were selected from groups which were arranged from a collection of three thousand models.

These forms are very common among the defective classes, such as the idiotic, deaf and dumb, blind, insane and criminal classes.

THE AUTHOR. 
PLATE I.

Illustrates the jaws in their normal position. 


\section{PLATE I}

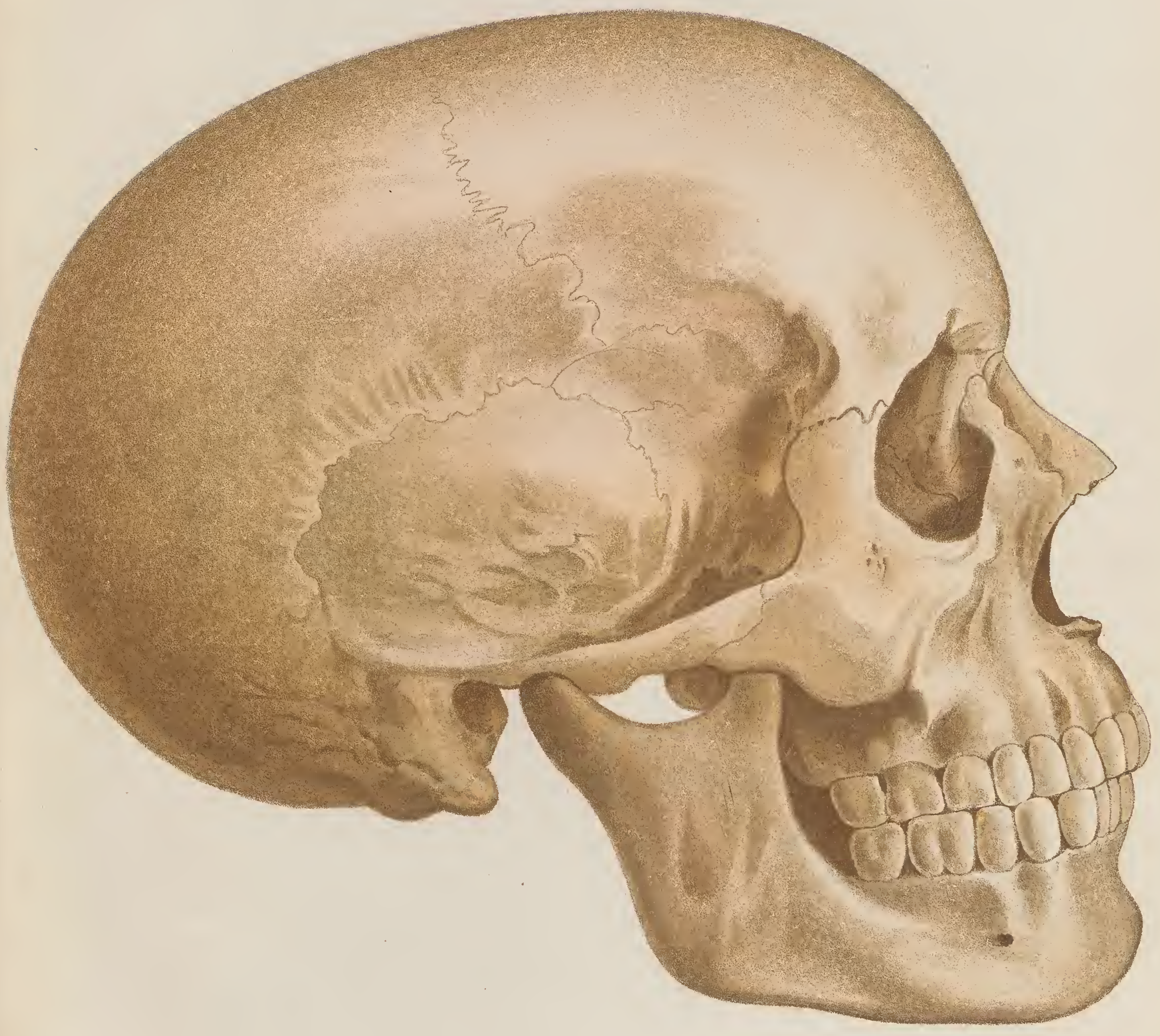


PLATE II.

Illustrates excessive development of the superior maxilla, and arrest of development of the body and rami of the inferior maxilla. When the second molars erupt, the anterior teeth separate, owing to a want of harmony in the development of the jaws. 


\section{PLATE II}

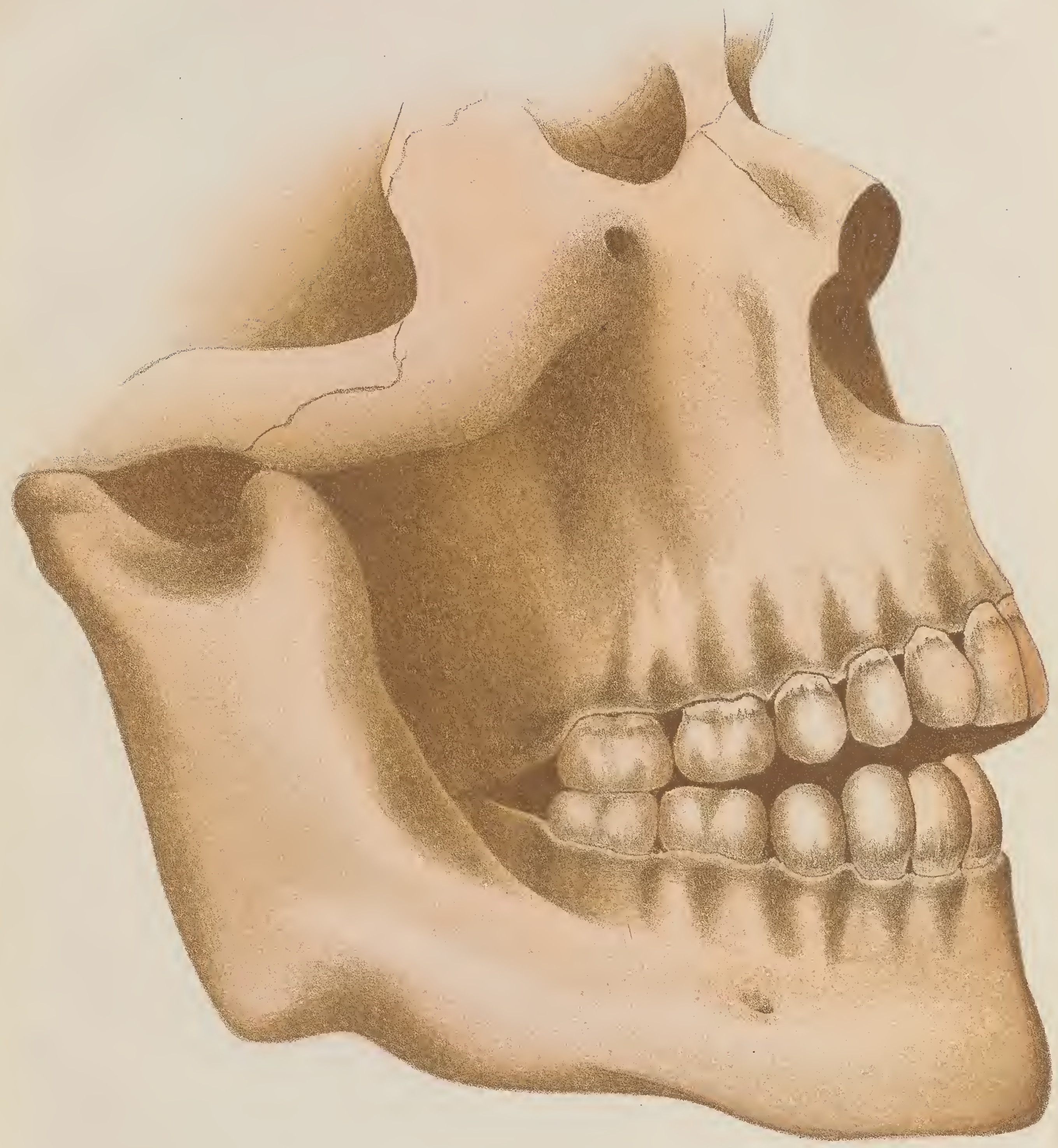




\section{PLATE III.}

Illustrates arrest of development of the superior maxilla, and the rami of the inferior maxilla and excessive development of the body of the jaw. The articulation was precisely the same as in Plate II, but the powerful lower jaw and the muscles have overcome the weaker superior jaw teeth and alveolar process, so that the upper alveolar process and teeth are forced forward until the articulation is complete. 


\section{PLATE III}

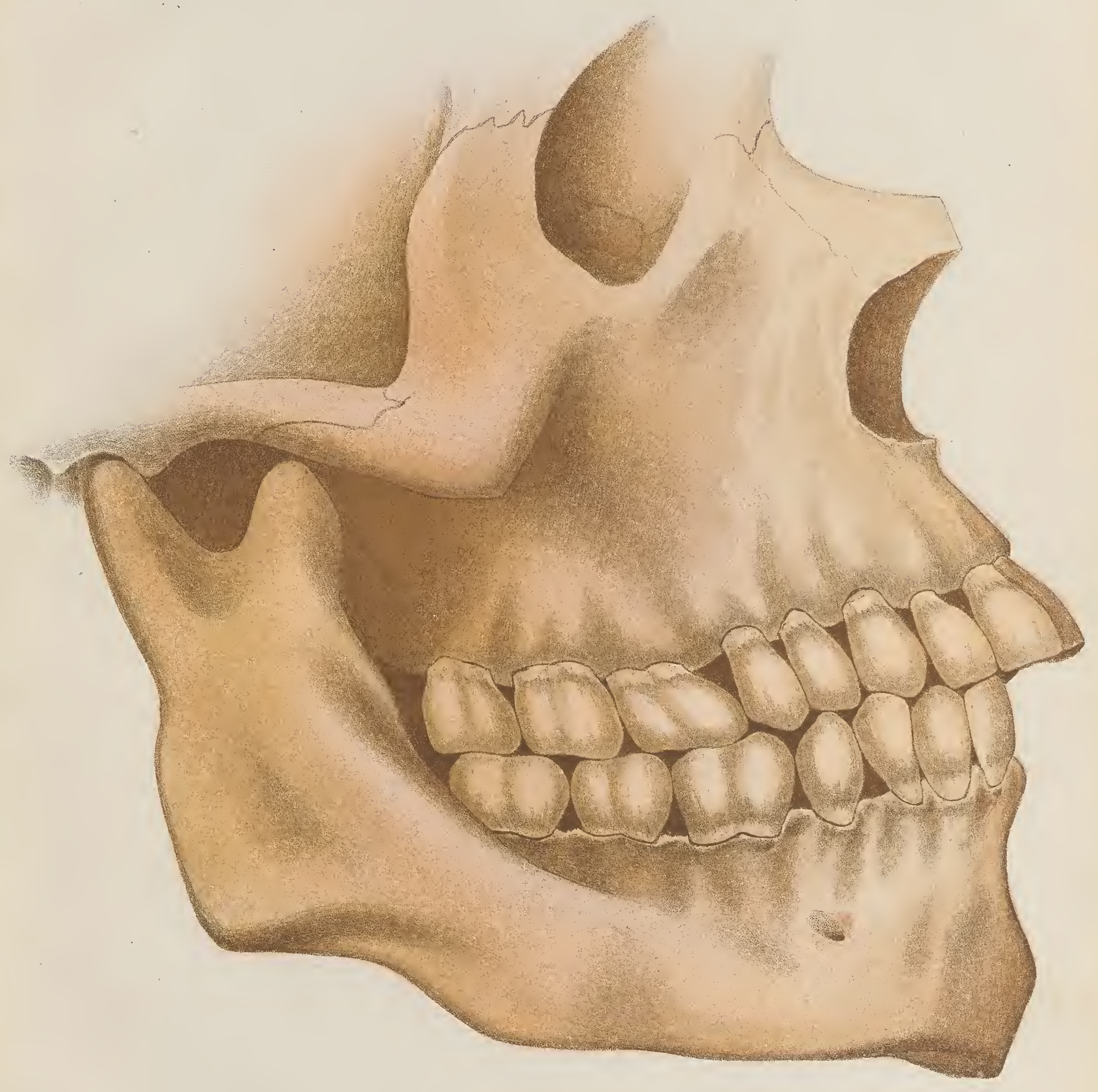


PIATE IV.

Illustrates excessive development of the rami of the inferior maxilla. The body of the jaw is carried forward and occlusion is possible only with the second superior molar, and the third inferior molar upon the right side. 


\section{PLATE IV}

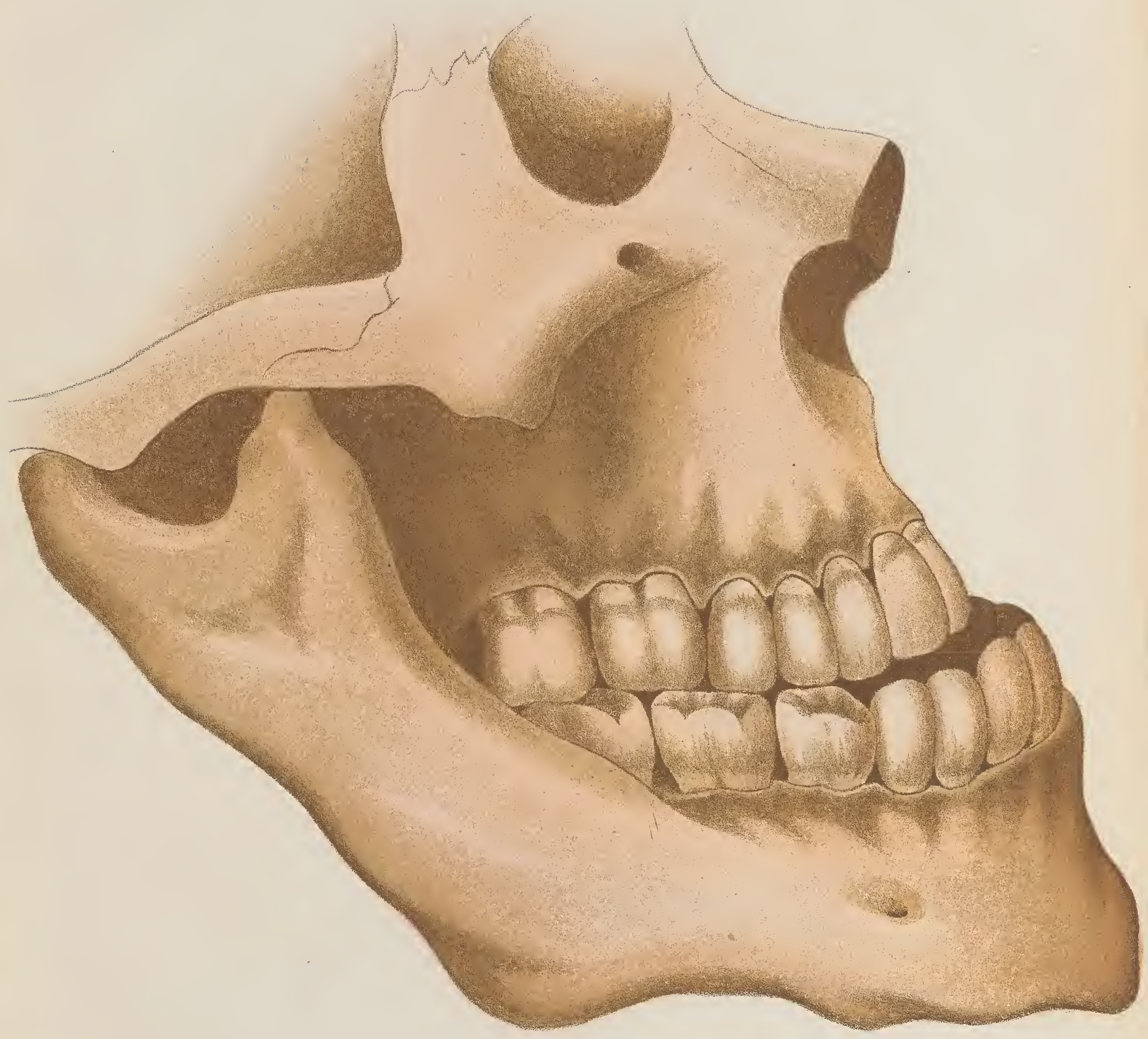


PLATE V.

Illustrates arrest of development of the inferior maxilla. The chin recedes to such an extent that a deformity is produced. 


\section{PLATE V}

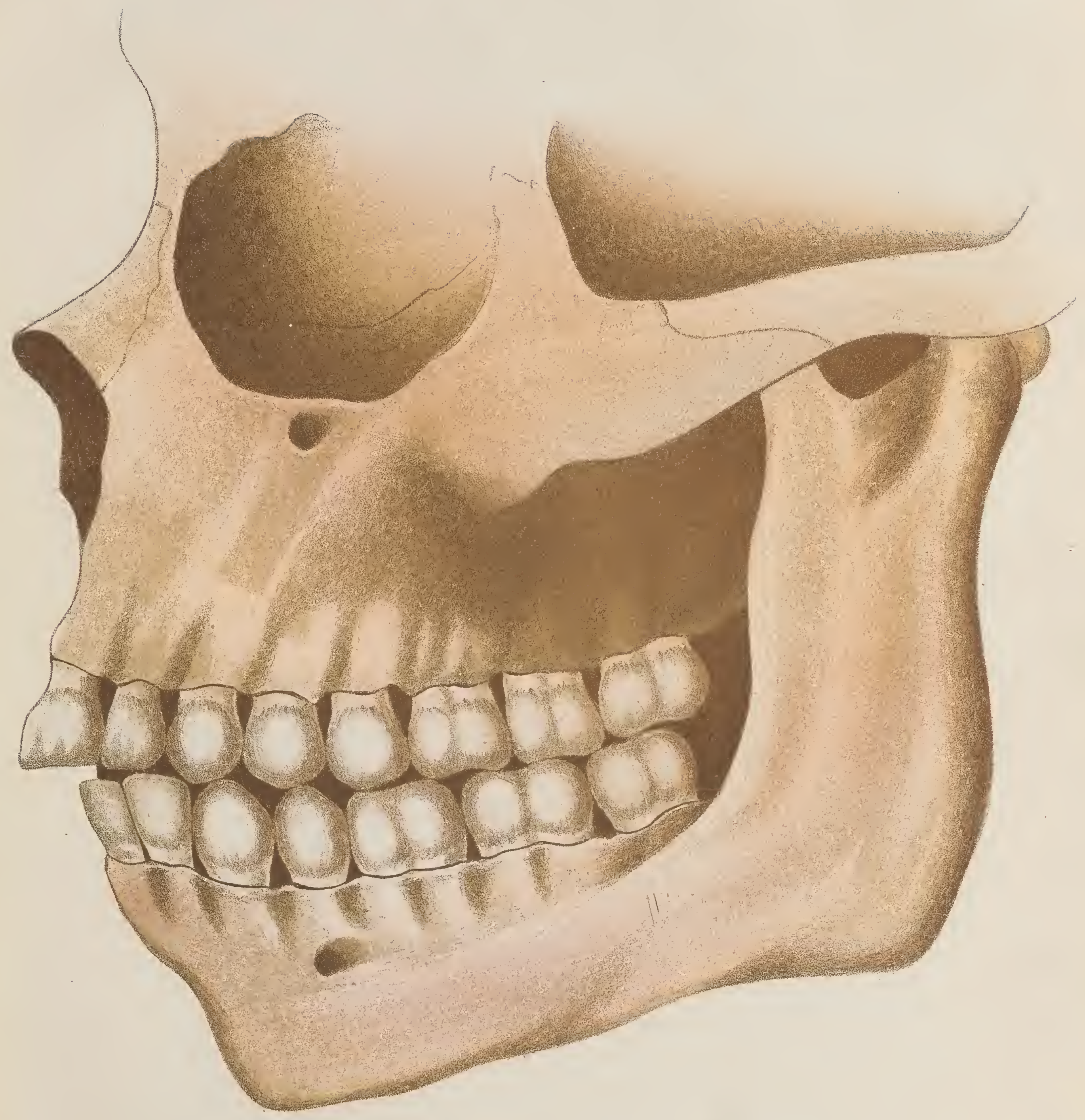


PLATE VI.

Illustrates arrest of development of the rami, which is compensated for by excessive development of the body of the inferior maxilla. The articulation is normal. 


\section{PLATE VI}

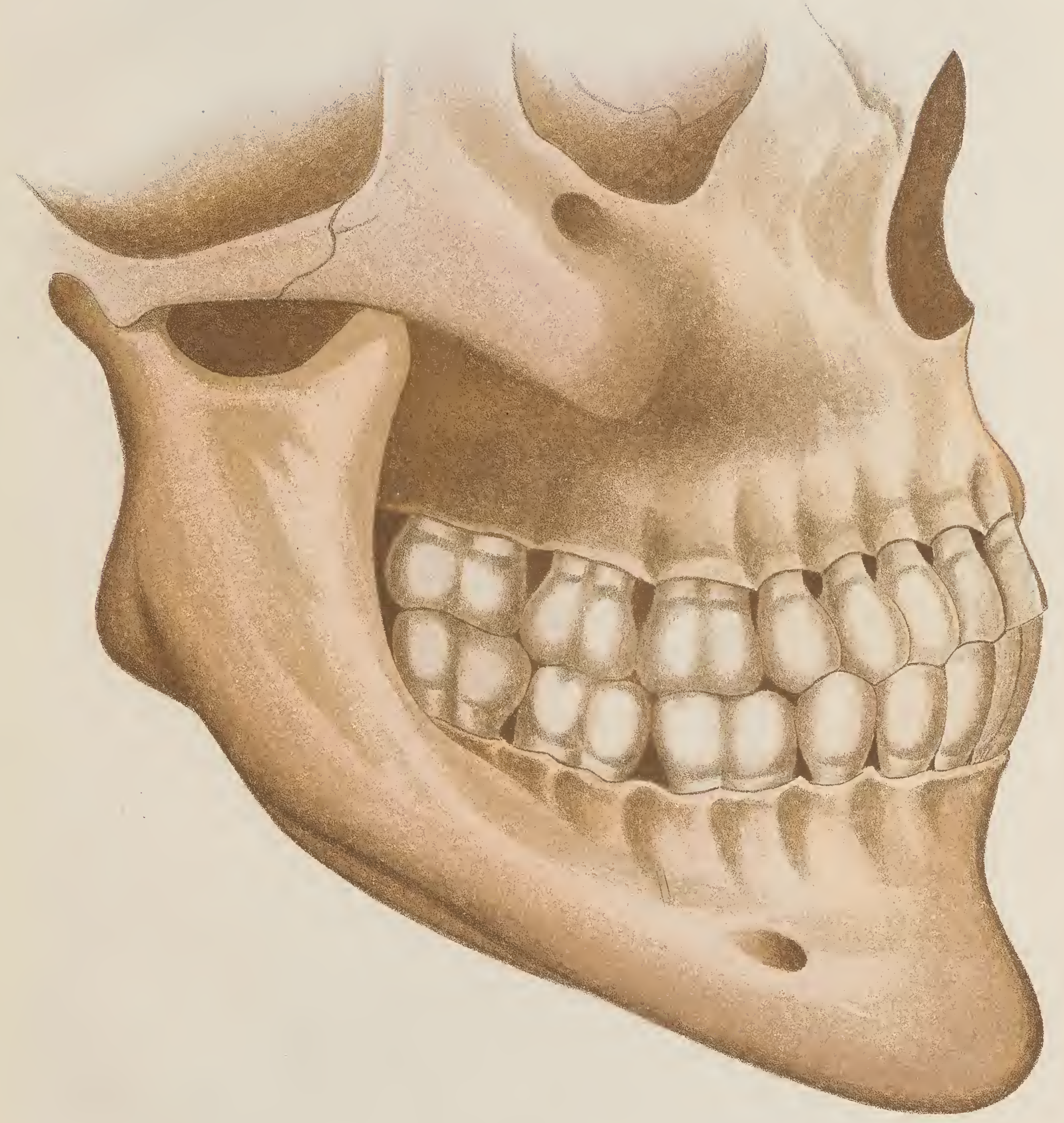


PLATE VII.

Illustrates excessive development of the superior maxilla, and alveolar process. The teeth overlap and the cutting edge of the incisors impinge upon the gum of the inferior maxilla. The inferior maxilla is normal. 


\section{PLATE VII}

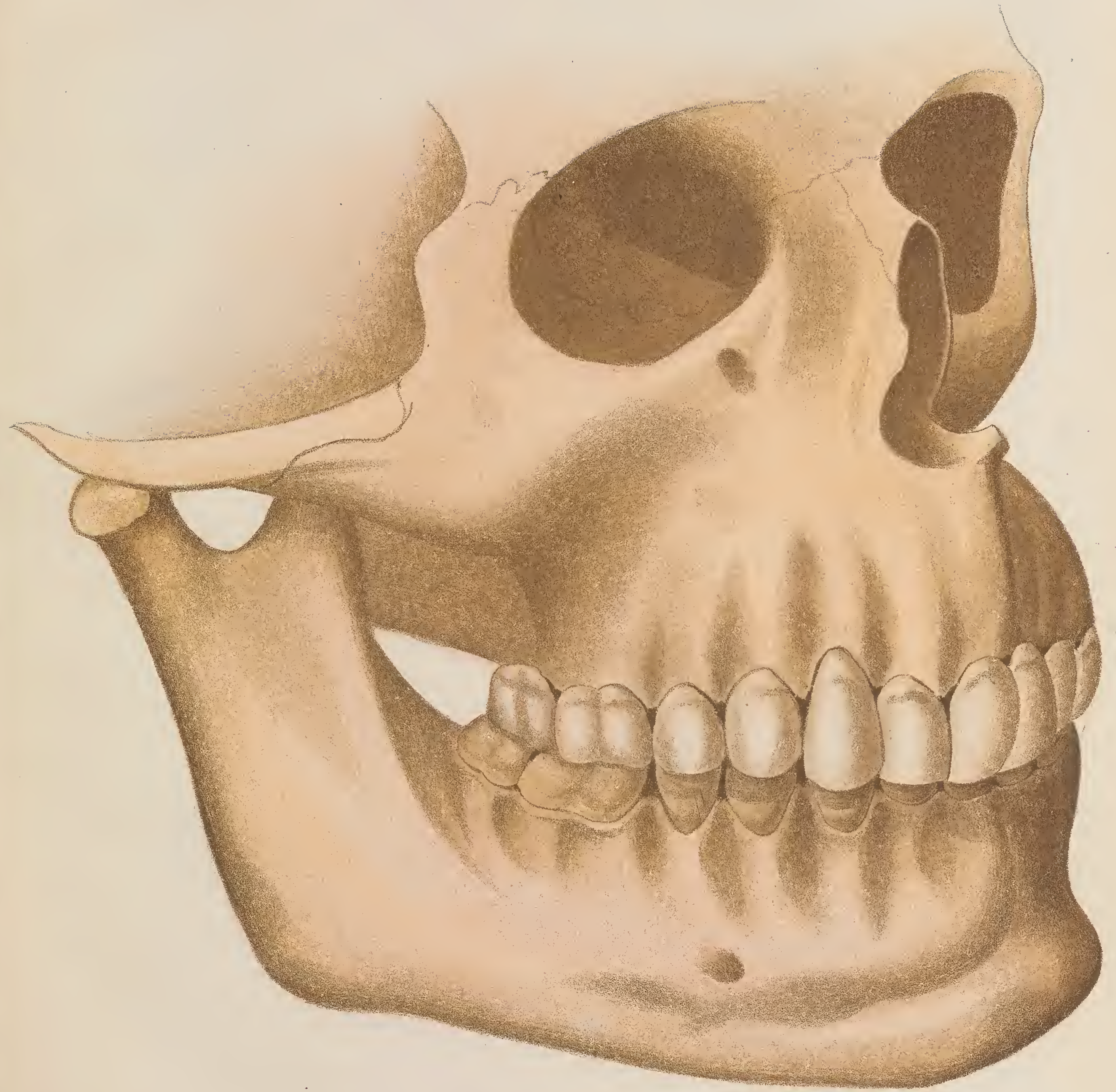




\section{PLATE VIII.}

Illustrates arrest of development of the superior maxilla. The inferior maxilla is normal, with excessive development of the anterior alveolar process. The inferior incisors impinge upon the gum of the superior maxilla. 


\section{PLATE VIII}

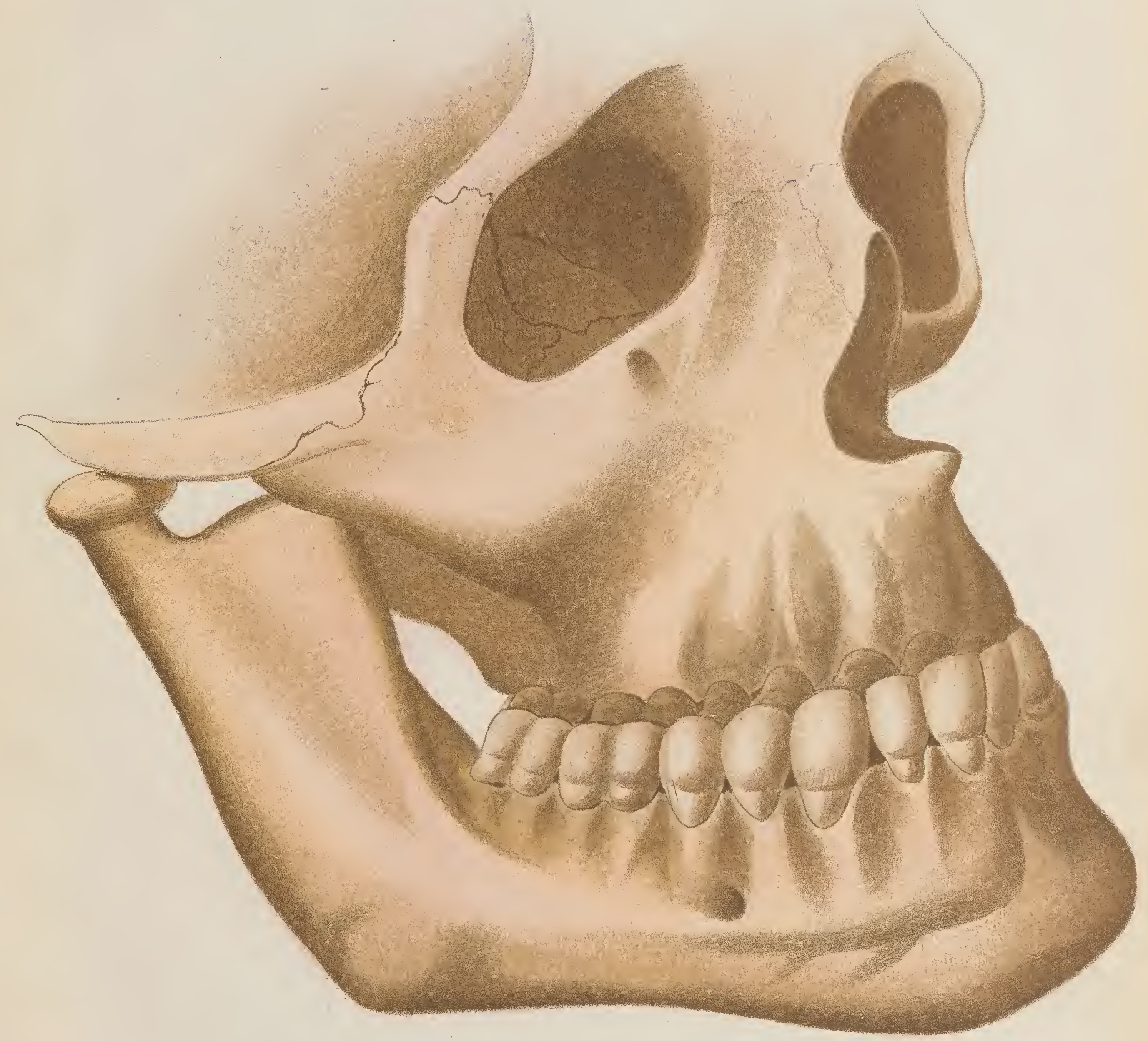


PLATE IX.

The V-shaped arch. 


\section{PLATE IX}

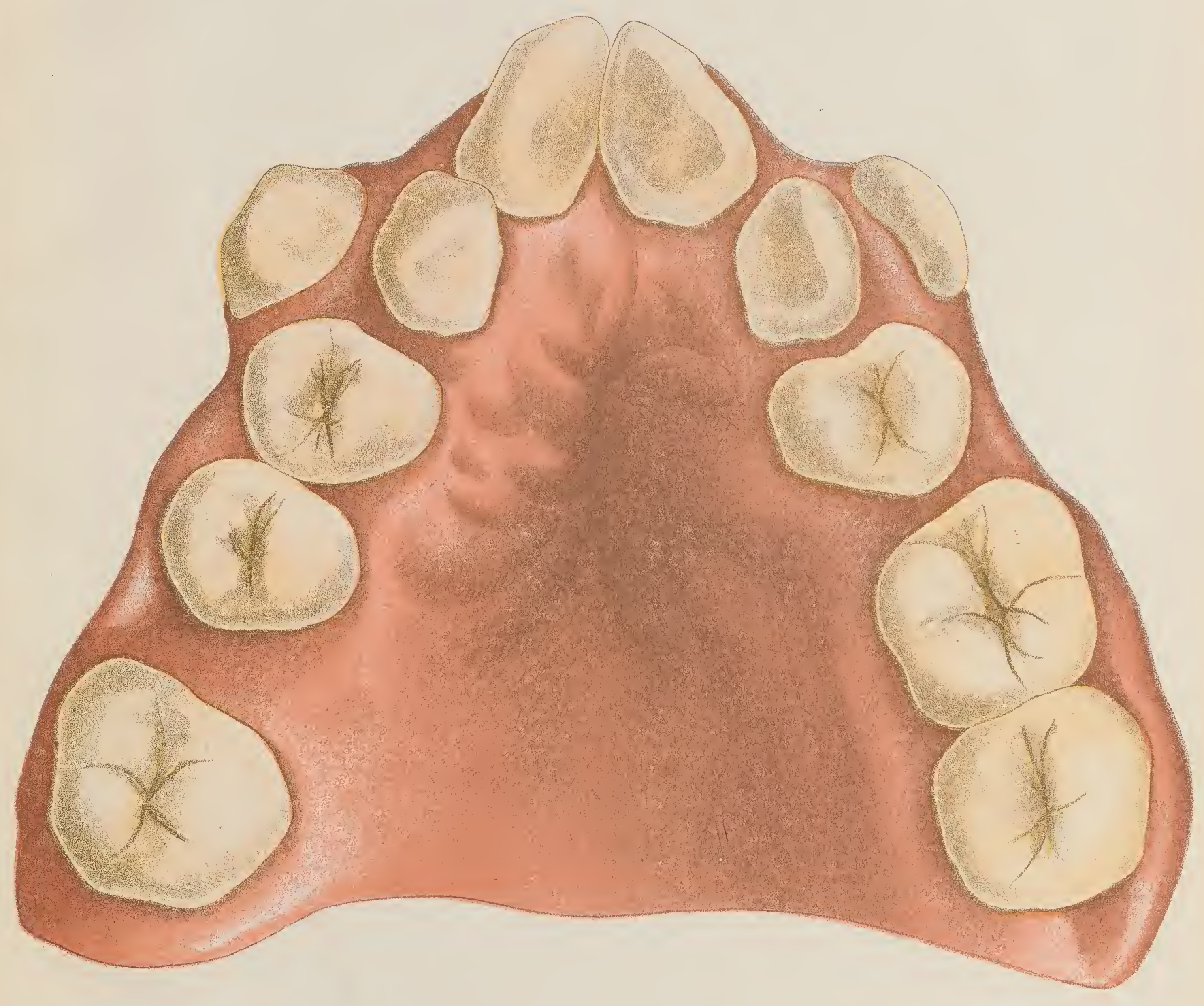


PLATE X.

The partial V-shaped arch. 


\section{PLATE X}

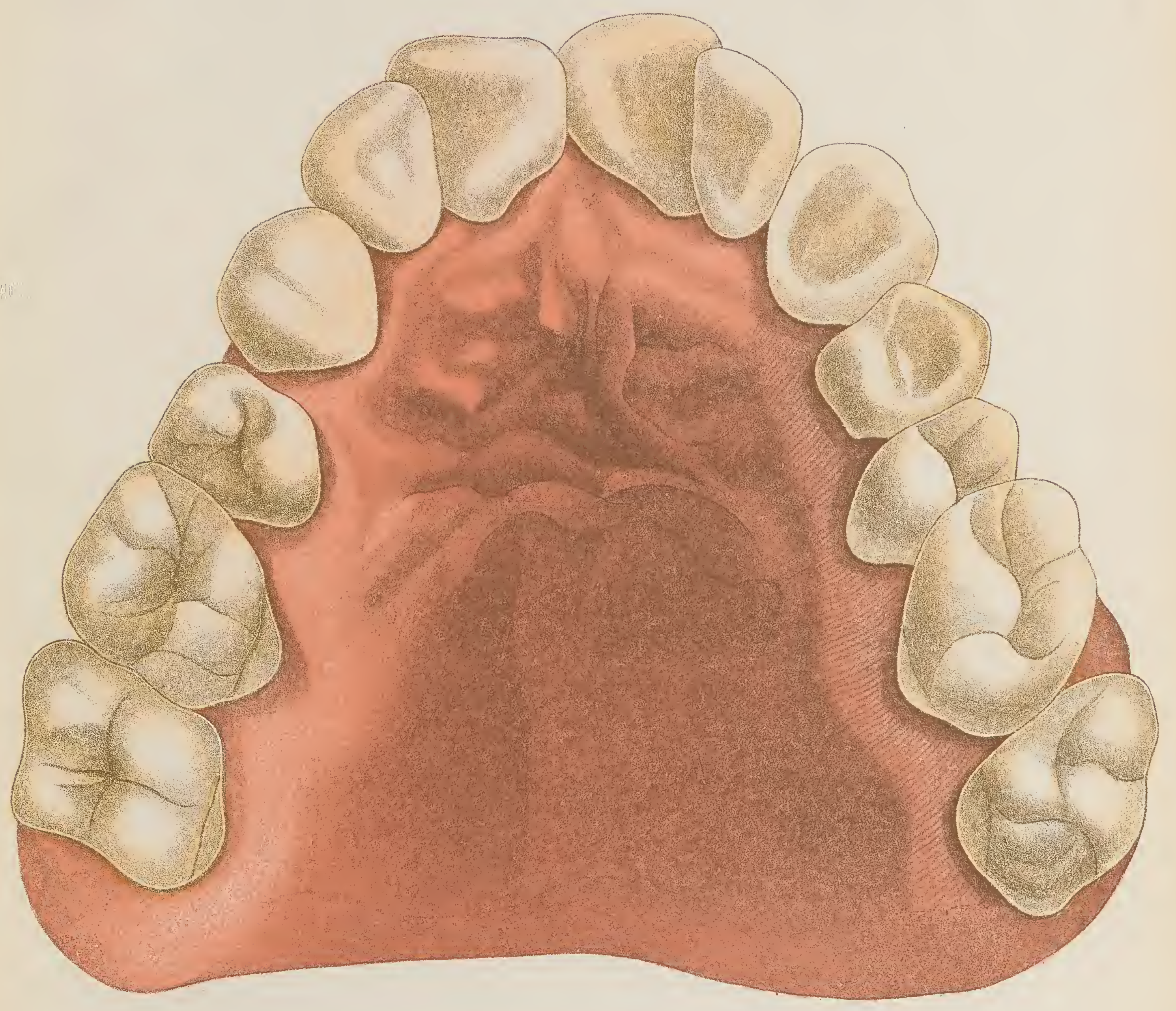


PLATE XI.

The semi V-shaped arch. 


\section{PLATE XI}

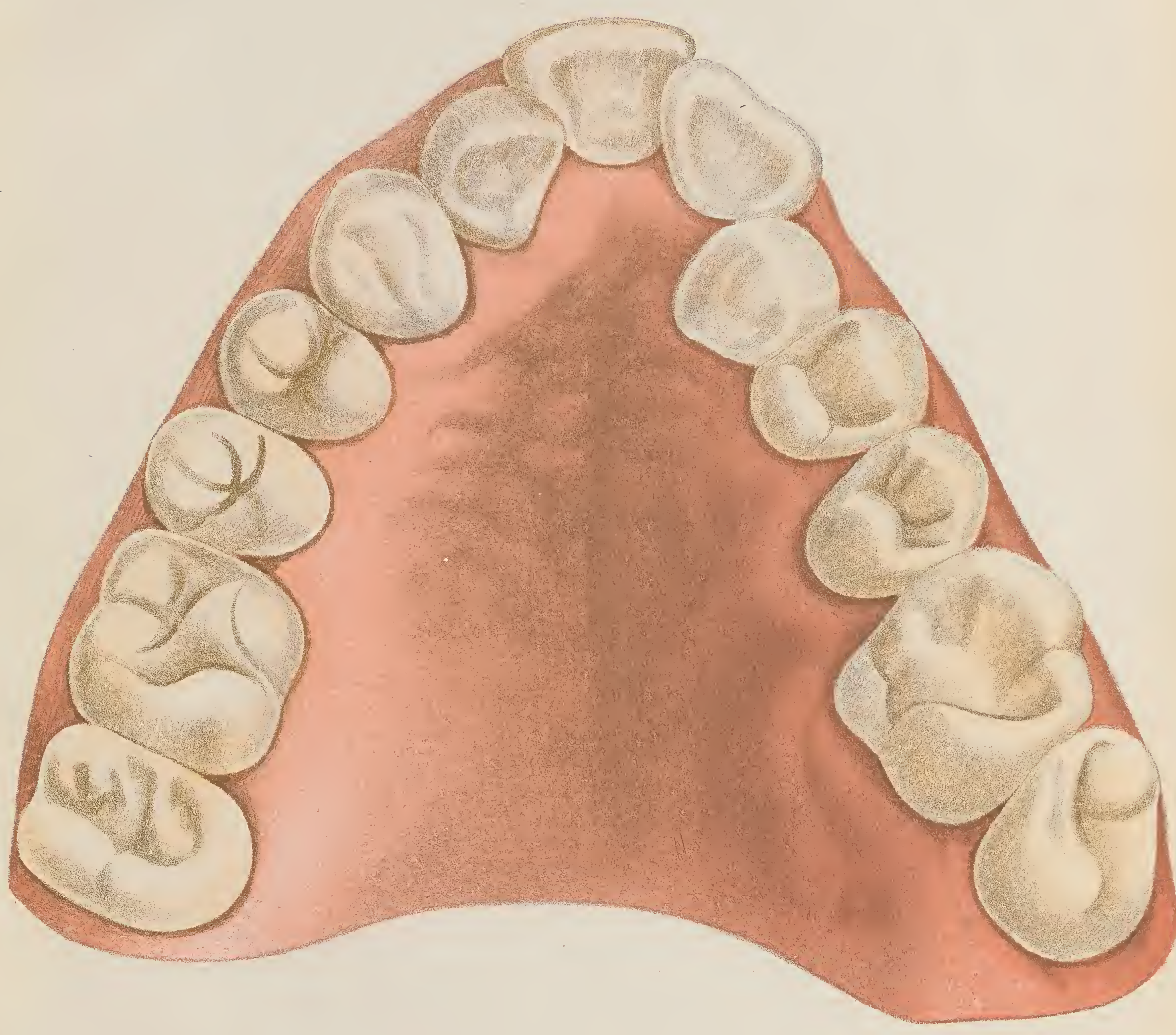


PLATE XII.

The saddle-shaped arch. 


\section{PLATE XII}

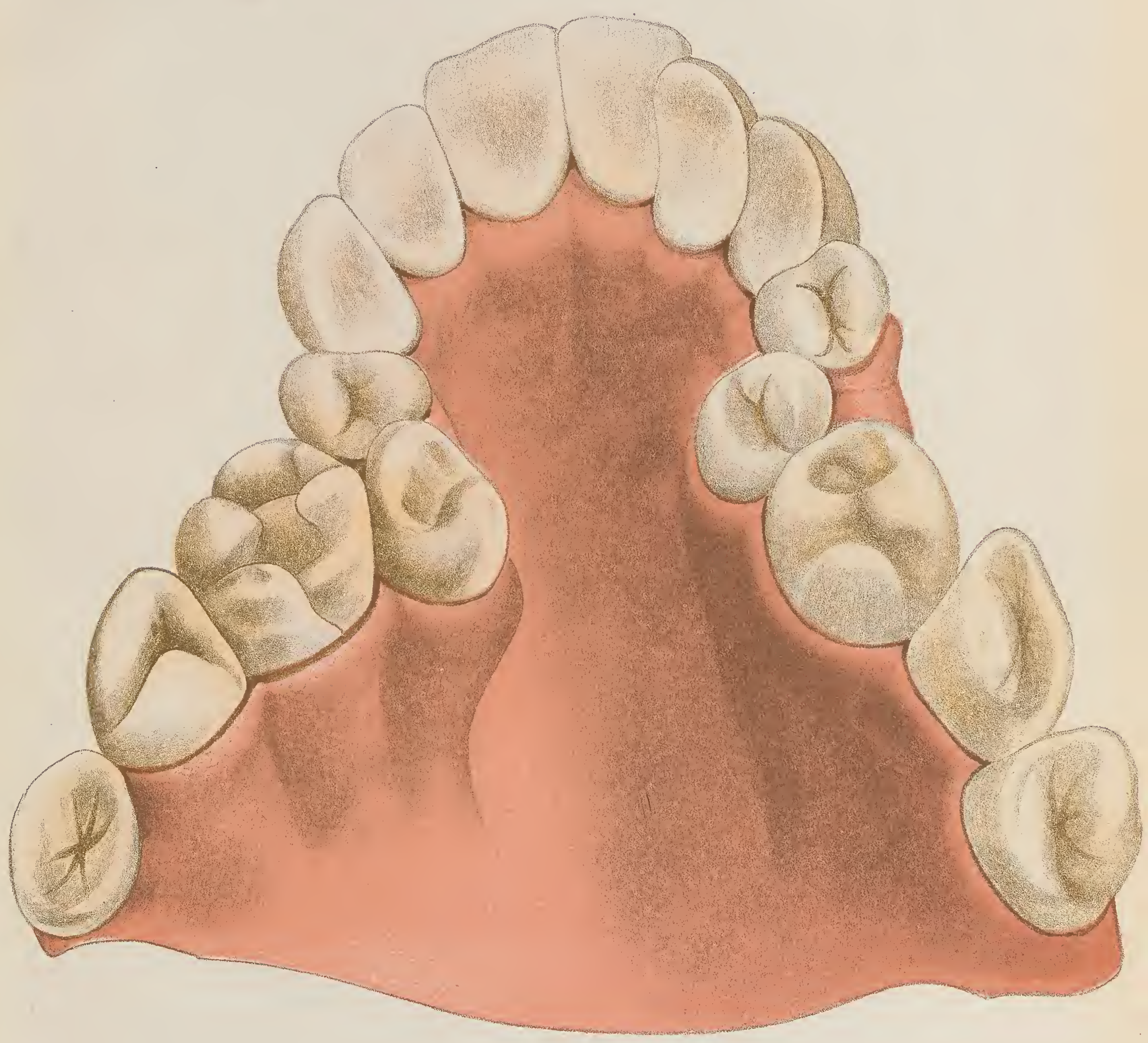


PLATE XIII.

The partial saddle-shaped arch. 


\section{PLATE XIII}

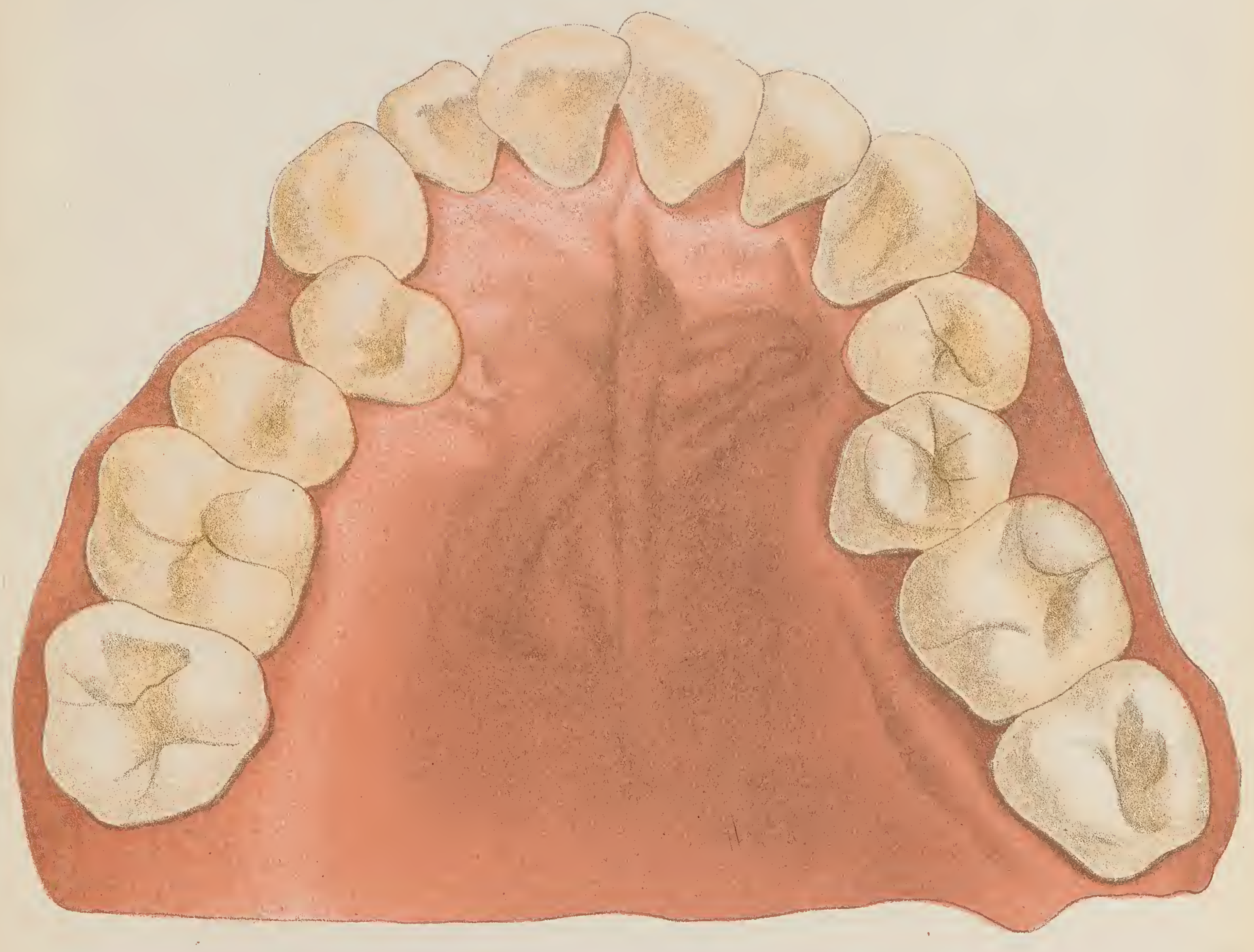


PLATE XIV.

The semi saddle-shaped arch. 


\section{PLATE XIV}

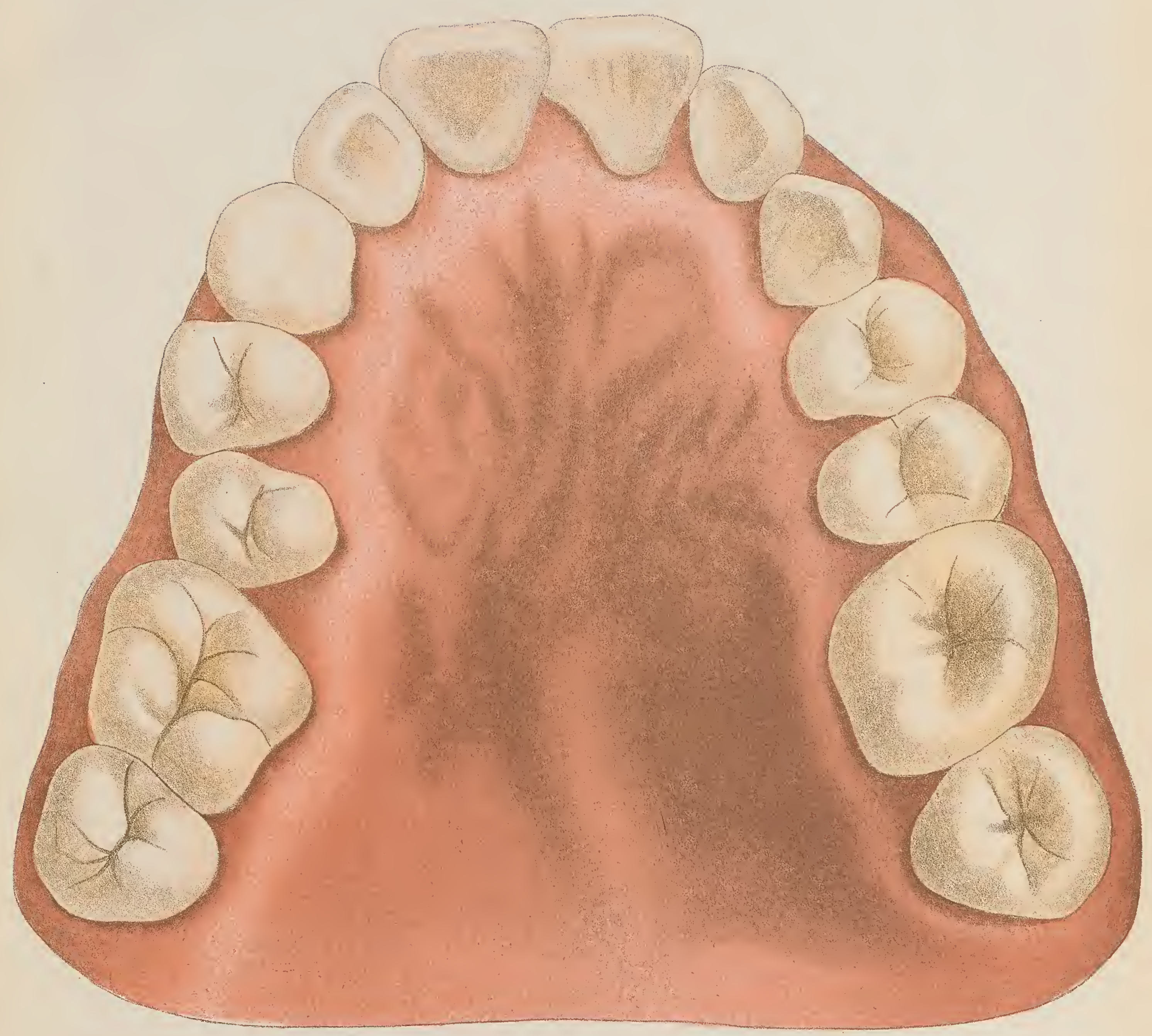




\section{PLATE XV.}

The semi V-and semi saddle-shaped arch on one side, and the semi V-shaped arch on the other side. 


\section{PLATE XV.}




The semi $V$-and semi saddle-shaped arch on one side, and the semi saddle-shaped arch upon the other side. 


\section{PLATE XVI}

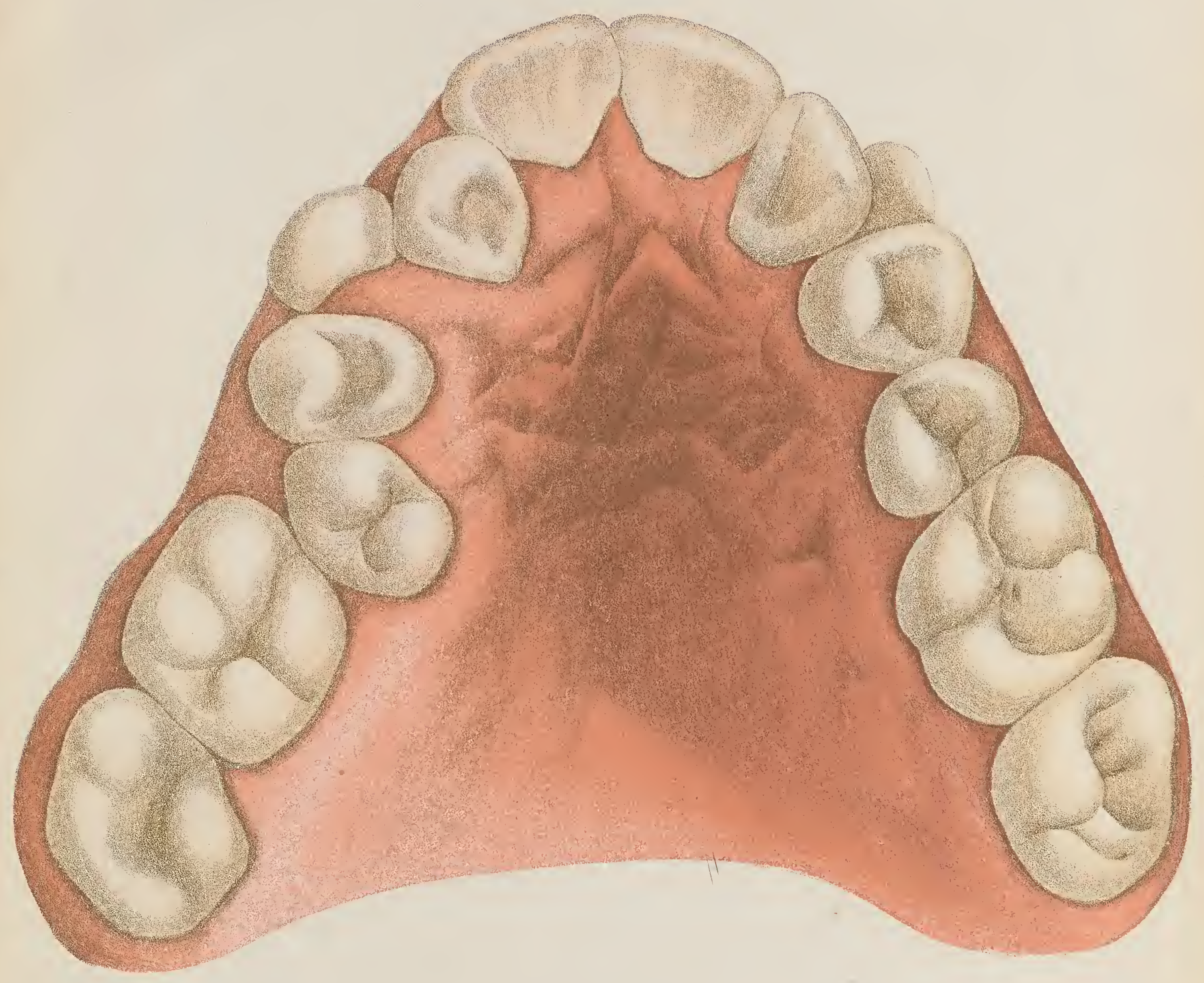



m. 

